\title{
RADIO EMISSION FROM INTERSTELLAR HYDROGEN \\ CYANIDE AND X-OGEN
}

\author{
LEWIS E.SNYDER \\ University of Virginia, \\ and \\ DAVID BUHL \\ National Radio Astronomy Observatory*
}

\begin{abstract}
Radio emission spectra from the $J=1-0$ transition of $\mathrm{H}^{12} \mathrm{C}^{14} \mathrm{~N}$ and $\mathrm{H}^{13} \mathrm{C}^{14} \mathrm{~N}$, two molecular isotopes of hydrogen cyanide, have been detected at 88.6 and $86.3 \mathrm{GHz}$, respectively. In addition, an emission signal from a new and unidentified interstellar molecule was detected at $89.2 \mathrm{GHz}$. The new molecule temporarily has been named 'X-ogen' until its chemical identity can be determined. $\mathrm{X}$-ogen has been detected in several regions and may be as common as hydrogen cyanide in the Galaxy.
\end{abstract}

We reported the detection of radio emission from interstellar hydrogen cyanide only two months ago $[1,2]$ so it is interesting to note that Townes suggested the potential radio astronomical interest of this molecule in 1955 at the IAU Symposium No. 4 [3]. In addition to hydrogen cyanide, we would like to discuss an emission line from another molecule which we will call X-ogen. Because we are still analyzing a portion of the data we would prefer to consider this discussion as a preliminary rather than a final report of our results.

The observations were made with the 36-ft telescope of the National Radio Astronomy Observatory at Kitt Peak, Arizona. At the frequency of the hydrogen cyanide emission the telescope beam has a nominal half-power width of $1^{\prime}$ of arc which is subject to variation with change in the ambient temperature. The resulting variation of the antenna efficiency was monitored during June, 1970, by observing Jupiter. Primarily because of the beam-width changes, the antenna temperatures which we are reporting are time averages taken over a three week period which have an uncertainty on the order of $50 \%$. The optimum beam efficiency was approximately $50 \%$. The pointing corrections were uncertain by $10^{\prime \prime}$ of arc.

The receiver used for the observations was a $3 \mathrm{~mm}$ radiometer developed by the National Radio Astronomy Observatory and the local oscillator was developed by NRAO with the assistance of the Bell Telephone Laboratories. The radiometer could be tuned from 85 through $90 \mathrm{GHz}$ with a single sideband noise temperature of approximately $4000 \mathrm{~K}$. The filter bank used for these observations consisted of 40 filters spaced $1 \mathrm{MHz}$ apart which covered a velocity range of $130 \mathrm{~km} / \mathrm{sec}$.

Currently we can report definite detections of the $J=1-0$ ground state rotational

* The National Radio Astronomy Observatory is operated by Associated Universities, Inc., under contract with the National Science Foundation. 
transition of $\mathrm{H}^{12} \mathrm{C}^{14} \mathrm{~N}$ at $88.6 \mathrm{GHz}(\sim 3.4 \mathrm{~mm})$ in six sources: W3 $(\mathrm{OH})$, Orion $\mathrm{A}$, Sgr $\mathrm{A}\left(\mathrm{NH}_{3} \mathrm{~A}\right), \mathrm{W} 49$, W51 and DR21 $(\mathrm{OH})$. We can find no $\mathrm{H}^{12} \mathrm{C}^{14} \mathrm{~N}$ emission to a lower limit of approximately $3 \mathrm{~K}$ antenna temperature in the direction of the following sources [4, 5]: W3, 3C273, L134, Sgr B2(OH), Sgr A, Sgr A ( $\mathrm{NH}_{3}$ B), M17, Cloud 1, and Cas A. However it is possible that weak signals from these sources will be found in our data when the averaging has been completed. The less abundant molecular isotope $\mathrm{H}^{13} \mathrm{C}^{14} \mathrm{~N}$ was detected in Orion $\mathrm{A}$ and $\mathrm{Sgr} \mathrm{A}\left(\mathrm{NH}_{3} \mathrm{~A}\right)$. The filter resolution was not sufficient to resolve the $F=1-1,2-1$, and $0-1$ quadrupole splitting [6] of $\mathrm{H}^{12} \mathrm{C}^{14} \mathrm{~N}$ at $88630.43,88631.87$ and $88633.95 \mathrm{MHz}$, respectively, and the corresponding transitions of $\mathrm{H}^{13} \mathrm{C}^{14} \mathrm{~N}$ at $86338.12,86339.49$ and $86341.54 \mathrm{MHz}$ [7].

While we were using the lower sideband of the receiver to observe $\mathrm{H}^{13} \mathrm{C}^{14} \mathrm{~N}$, a new line appeared in the upper sideband. The line was definitely detected in $\mathrm{W} 3(\mathrm{OH})$, Orion A, Sgr A $\left(\mathrm{NH}_{3} \mathrm{~A}\right)$, W51, and probably detected in the dark cloud L134. A rest frequency of $89.190 \pm 0.002 \mathrm{GHz}$ was determined by averaging the values found from profile-matching with the HCN. Because we are unable to make a positive identification of the molecule which is emitting this new line we have named it the X-ogen line, which means line of unknown extraterrestrial origin.

We believe that $\mathrm{X}$-ogen is not an atomic line because the only known atomic recombination line of any possible significance near the $89.190 \mathrm{GHz}$ transition of $\mathrm{X}$-ogen is the $\mathrm{H} 59 \alpha$ at $89.199 \mathrm{GHz}$ [8]. In addition to the frequency discrepancy, $\mathrm{H} 59 \alpha$ would not be expected to have the strong intensity and sharp profile of the $\mathrm{X}$-ogen line. X-ogen cannot be explained by doppler-shifted hydrogen cyanide because the velocity ofiset from the local standard of rest would have to be $1690 \mathrm{~km} \mathrm{sec}^{-1}$ in the case of $\mathrm{H}^{12} \mathrm{C}^{14} \mathrm{~N}$. Such an offset for a galactic gas cloud is highly unlikely. We rule out transitions of any rare isotope of hydrogen cyanide because there are no known isotopic transitions at the X-ogen frequency. Finally, we do not believe that $\mathrm{X}$-ogen is a 'hot band' rotational transition of HCN because of the large amount of excitation energy required (The lowest vibrational state for $\mathrm{HCN}$ is $v_{2}$ at $569 \mathrm{~cm}^{-1}$ above the zero-point vibrational energy).

On the basis of our present data we cannot rule out the possibility that the X-ogen line is masering. The X-ogen line is consistently narrower than the HCN line in the same source but this may result from several unresolved components in the HCN line which would make the present profile comparisons very misleading. In addition, higher frequency resolution may reveal fine structure in the X-ogen line. Source mapping should yield valuable information on the spatial extent of the emission. If masering can be ruled out, then there is a possibility that X-ogen may be a heavier molecule than HCN but this probably does not explain the narrower features because interstellar line profiles are usually influenced more by turbulent broadening than by thermal widths. To add to the identification problem, it is possible that we have not detected the main molecular isotope of X-ogen but a less common member instead.

The hydrogen cyanide and X-ogen observations of primary interest are summarized in Table I. For comparison; we have also listed appropriate interstellar formaldehyde $\left(\mathrm{H}_{2}{ }^{12} \mathrm{C}^{16} \mathrm{O}\right)$, ammonia $\left({ }^{14} \mathrm{NH}_{3}\right)$ and carbon monoxide $\left({ }^{12} \mathrm{C}^{16} \mathrm{O}\right)$ radial velocity meas- 
urements from the recent literature $[4,9,10]$. If more extensive comparison is desired reference No. 4 should be consulted for an excellent compendium of $\mathrm{H}_{2} \mathrm{CO}, \mathrm{HI}, \mathrm{OH}$, $\mathrm{H}$ II, C, $\mathrm{H}_{2} \mathrm{O}$ and $\mathrm{NH}_{3}$ radial velocity measurements. The source names are listed in Column 1 followed by the epoch 1950 right ascensions and declinations in Columns 2 and 3. The molecular species are given in Column 4 and the following column lists the measured antenna temperatures (subject to the $50 \%$ uncertainty discussed earlier) for individual hydrogen cyanide or $\mathrm{X}$-ogen spectral features. The radial velocities of individual spectral features are listed in Column 6 . The hydrogen cyanide radial velocities are uncertain to $\pm 3 \mathrm{~km} \mathrm{sec}^{-1}$ in contrast to approximately $\pm 7 \mathrm{~km} \mathrm{sec}^{-1}$ error for $\mathrm{X}$-ogen due to the experimental inaccuracies involved in determining the rest frequency. The line width at half maximum intensity for each spectral feature in Column 6 is given in Column 7. Estimated hydrogen cyanide projected densities (number density integrated along the line of sight) for the $J=1-0$ transition only are given in Column 8. Figure 1 illustrates the spectral lines of $\mathrm{H}^{12} \mathrm{C}^{14} \mathrm{~N}, \mathrm{H}^{13} \mathrm{C}^{14} \mathrm{~N}$ and $\mathrm{X}$-ogen found against Orion $\mathrm{A}$. The line temperatures are attenuated by approxi-

TABLE I

\begin{tabular}{|c|c|c|c|c|c|c|c|}
\hline Source & $\alpha_{1950}$ & $\delta_{1950}$ & Molecule & $\begin{array}{l}\text { Antenna } \\
\text { temperature } \\
\text { (Kelvin) }\end{array}$ & $\begin{array}{l}\text { Radial } \\
\text { velocity } \\
\left(\mathrm{km} \mathrm{sec}^{-1}\right)\end{array}$ & $\begin{array}{l}\text { Line } \\
\text { width } \\
\left(\mathrm{km} / \mathrm{sec}^{-1}\right)\end{array}$ & $\begin{array}{l}\text { Projected } \\
\text { density } \\
\left(\text { No. } / \mathrm{cm}^{2}\right)\end{array}$ \\
\hline $\mathrm{W} 3(\mathrm{OH})$ & $2^{\mathrm{h} 23^{\mathrm{m}}} 17^{\mathrm{s}}$ & $61^{\circ} 39^{\prime} 00^{\prime \prime}$ & $\begin{array}{l}\mathrm{H}^{12} \mathrm{C}^{14} \mathrm{~N} \\
\mathrm{X} \text {-ogen } \\
\mathrm{H}_{2}{ }^{12} \mathrm{C}^{16} \mathrm{O}\end{array}$ & $\begin{array}{l}3 \\
4\end{array}$ & $\begin{array}{l}-49 \\
-44 \\
-47.8\end{array}$ & $\begin{array}{r}14 \\
8 \\
4\end{array}$ & $1.8 \times 10^{13}$ \\
\hline Orion $\mathrm{A}^{\mathrm{a}}$ & $5^{\mathrm{h}} 32^{\mathrm{m}} 47^{\mathrm{s}}$ & $-5^{\circ} 24^{\prime} 21^{\prime \prime}$ & $\begin{array}{l}\mathrm{H}^{12} \mathrm{C}^{14} \mathrm{~N} \\
\mathrm{H}^{13} \mathrm{C}^{14} \mathrm{~N} \\
\mathrm{X}-\text { ogen } \\
{ }^{12} \mathrm{C}^{16} \mathrm{O}\end{array}$ & $\begin{array}{l}7(\times 2) \\
1(\times 2) \\
6(\times 2)\end{array}$ & $\begin{array}{l}12 \\
12 \\
12 \\
10.5\end{array}$ & $\begin{array}{c}14 \\
15 \\
7 \\
6.2\end{array}$ & $\begin{array}{l}8.2 \times 10^{13} \\
1.3 \times 10^{13}\end{array}$ \\
\hline $\operatorname{Sgr} A\left(N_{3} \mathrm{~A}\right)$ & $17^{\mathrm{h}} 42^{\mathrm{m}} 28^{\mathrm{s}}$ & $-29^{\circ} 01^{\prime} 30^{\prime \prime}$ & $\begin{array}{l}\mathrm{H}^{12} \mathrm{C}^{14} \mathrm{~N} \\
\mathrm{X} \text {-ogen } \\
\mathrm{H}_{2}{ }^{12} \mathrm{C}^{16} \mathrm{O} \\
{ }^{14} \mathrm{NH}_{3}\end{array}$ & $\begin{array}{l}8 \\
3\end{array}$ & $\begin{array}{l}26 \\
27 \\
34.7^{\mathrm{c}} \\
23^{d}\end{array}$ & $\begin{array}{l}40^{b} \\
34 \\
42.5 \\
25\end{array}$ & $1.3 \times 10^{14}$ \\
\hline W49 & $19^{\mathrm{h}} 07^{\mathrm{m}} 53^{\mathrm{s}}$ & $09^{\circ} 01^{\prime} 00^{\prime \prime}$ & $\begin{array}{l}\mathrm{H}^{12} \mathrm{C}^{14} \mathrm{~N} \\
\mathrm{H}_{2}{ }^{12} \mathrm{C}^{16} \mathrm{O}\end{array}$ & 6 & $\begin{array}{c}5 \\
13.8\end{array}$ & $\begin{array}{l}17 \\
7.6\end{array}$ & $4.2 \times 10^{13}$ \\
\hline W51 & $19^{\mathrm{h}} 21^{\mathrm{m}} 27^{\mathrm{s}}$ & $14^{\circ} 24^{\prime} 30^{\prime \prime}$ & $\begin{array}{l}\mathrm{H}^{12} \mathrm{C}^{14} \mathrm{~N} \\
\mathrm{X} \text {-ogen } \\
\mathrm{H}_{2}{ }^{12} \mathrm{C}^{16} \mathrm{O}\end{array}$ & $\begin{array}{l}5 \\
5\end{array}$ & $\begin{array}{l}55 \\
61 \\
65.4\end{array}$ & $\begin{array}{c}16 \\
12 \\
7.8\end{array}$ & $3.3 \times 10^{13}$ \\
\hline DR21 $(\mathrm{OH})$ & $20^{\mathrm{h}} 37^{\mathrm{m}} 14^{\mathrm{s}}$ & $42^{\circ} 12^{\prime} 00^{\prime \prime}$ & $\begin{array}{l}\mathrm{H}^{12} \mathrm{C}^{14} \mathrm{~N} \\
\mathrm{H}_{2}{ }^{12} \mathrm{C}^{16} \mathrm{O}\end{array}$ & 5 & $\begin{array}{l}-1 \\
-3.2\end{array}$ & $\begin{array}{l}12 \\
3.1\end{array}$ & $2.5 \times 10^{13}$ \\
\hline
\end{tabular}

a As noted in the table by $(\times 2)$, the antenna temperatures must be doubled to account for the attenuation of the dome. See Figure 1 for the Orion $\mathrm{A}$ spectra of $\mathrm{H}^{12} \mathrm{C}^{14} \mathrm{~N}, \mathrm{H}^{13} \mathrm{C}^{14} \mathrm{~N}$ and X-ogen. b This spectrum is not resolved; hence it probably contains more than one feature but the signal-tonoise ratio in our present data is inadequate to provide more than a qualitative estimate of the line width of the composite profile.

c This is the radial velocity of the main $\mathrm{H}_{2} \mathrm{CO}$ absorption feature. Four other absorption features have also been reported [4].

d Radial velocity of the $(1,1)$ transition of $\mathrm{NH}_{3}$. 

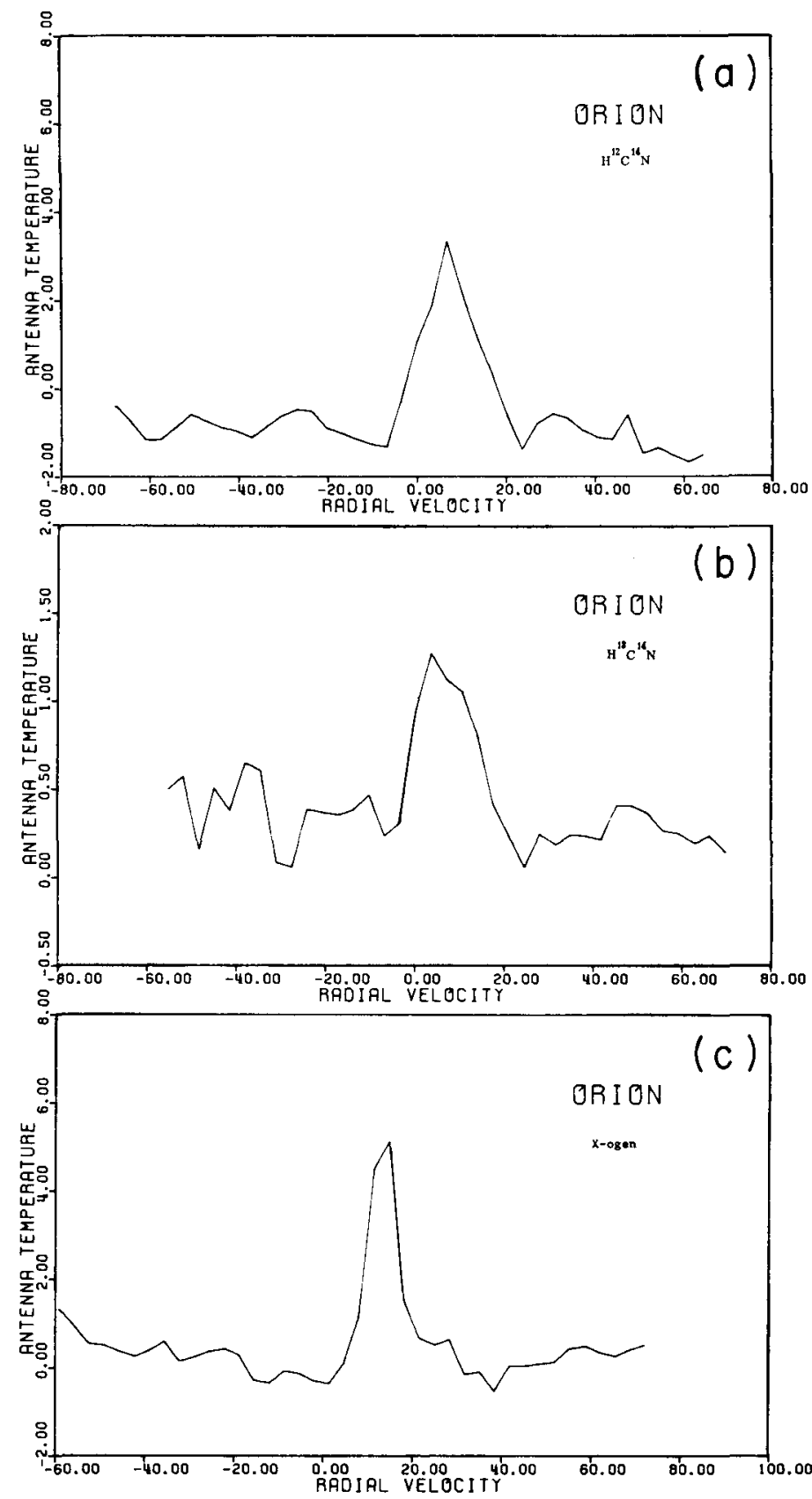

Fig. 1. Orion A spectra. The ordinate is antenna temperature (Kelvin) and the abscissa is radial velocity $\left(\mathrm{km} / \mathrm{sec}\right.$ ) with respect to the local standard of rest. (a) $\mathrm{H}^{12} \mathrm{C}^{14} \mathrm{~N}$ (b) $\mathrm{H}^{13} \mathrm{C}^{14} \mathrm{~N}$ (c) X-ogen. 
mately a factor of two because the spectra shown were taken with the telescope dome closed.

Because HCN is a linear molecule and the quadrupole splitting is relatively small, the selection rules for electric dipole transitions seem to rule out the pumping models which are currently advocated for interstellar $\mathrm{OH}$ and $\mathrm{H}_{2} \mathrm{CO}$; hence maser action is probably not significant and we can make some estimate of the projected densities. However, such an estimate as we have given in Table I from our $J=1-0$ emission spectra necessarily involves key assumptions. From an observational standpoint we must assume that the $\mathrm{HCN}$ is uniformly distributed with negligible 'clumping' and fills the telescope beam (which may not be true) such that the antenna temperature, $T_{A}$, corresponding to an emission line is given by

$$
T_{A}=\eta T_{\mu}\left(1-e^{-\tau}\right)
$$

where $\eta$ is the telescope efficiency, $T_{\mu}$ the excitation temperature and $\tau$ the optical depth. If we assume a small optical depth, in the usual way we can solve for the fractional projected density

$$
(N L) \cdot f=\frac{3 c k T_{A} \Delta v}{8 \pi^{3} \eta v^{2}|\mu|^{2}}
$$

where $c$ is the speed of light, $k$ is Boltzmann's constant, $\Delta v$ the line width at half maximum intensity, $v$ the rest frequency and $|\mu|$ the dipole-moment matrix element connecting the $J=0$ and $J=1$ energy levels. The projected densities in Table I are the product of $(N L)$, the projected density of the total number of HCN molecules in a given source, and $f$, the fraction of the total number measured by our data. For example, if the population distribution over the $\mathrm{HCN}$ energy levels were given by Boltzmann statistics, $f$ would be about 0.08 for an excitation temperature of $25 \mathrm{~K}$ and the projected density of the total number of $\mathrm{HCN}$ molecules for each source could be found simply by multiplying the fractional projected densities in Table I by 11.74. Since we can not at present measure the population distribution over the $\mathrm{HCN}$ energy levels, the $(N L) \cdot f$ value listed for each source may be regarded as a lower bound on the total $\mathrm{HCN}$ projected density. If the HCN emission is saturated, then the small optical depth assumption is not valid and Equation (2) does not apply. We expect that future measurements of the relative intensities of the $\mathrm{HCN}$ quadrupole components will be useful for detecting saturated emission. At present, in the Orion spectra (Figure 1 and Table $\mathrm{I}$ ) some evidence for saturation of $\mathrm{H}^{12} \mathrm{C}^{14} \mathrm{~N}$ is suggested by the $\mathrm{C}^{12} / \mathrm{C}^{13}$ isotopic abundance ratio of 6.4 which is much lower than the terrestrial value of 89. A plausible model, discussed in detail elsewhere [11], explains how a microwave spectrum from dense, 'clumpy' clouds of the $\mathrm{C}^{12}$ molecular isotope might lead to a low measured number for the $\mathrm{C}^{12} / \mathrm{C}^{13}$ ratio and yet be consistent with a true isotopic abundance which is much higher. On the other hand, there is no strong argument that 'true' isotopic abundance ratios should be terrestrial for interstellar molecules.

In conclusion, we note that the velocity agreement between $\mathrm{HCN}$ and $\mathrm{H}_{2} \mathrm{CO}$ in 
Table $I$ is not particularly good which may indicate that these two molecules have been detected in slightly different regions for a given radio source. The $\mathrm{X}$-ogen velocities are not yet determined accurately enough to allow us to make similar comparisons. Higher resolution spectra are needed to resolve the HCN quadrupole components and to aid in the identification of X-ogen. Mapping is necessary to learn more about the spatial extent of both molecules. We expect that many more HCN and $\mathrm{X}$-ogen sources will be found as millimeter-wave receiver quality improves and careful correlation between $\mathrm{HCN}$ and $\mathrm{CN}$ sources [12] should provide helpful clues toward understanding chemical processes in galactic gas clouds.

Note added in proof. We have recently detected $\mathrm{HCN}$ emission from $\mathrm{Sgr} \mathrm{B} 2(\mathrm{OH})$ and from the infrared object IRC +10216 .

\section{References}

[1] Buhl, D. and Snyder, L. E.: 1970, International Astronomical Union Circular No. 2251.

[2] Buhl, D. and Snyder, L. E.: 1970, Late paper presented at the 132nd Meeting of the American Astronomical Society, Boulder, Colo.

[3] Townes, C. H.: 1957, IAU Symposium No. 4, in Radio Astronomy (ed. by H. C. van de Hulst), Cambridge University Press, Cambridge, England.

[4] Zuckerman, B., Buhl, D., Palmer, P., and Snyder, L. E.: 1970, Astrophys. J. 160, 485.

[5] Palmer, P., Zuckerman, B., Buhl, D., and Snyder, L. E.: 1969, Astrophys. J. 156, L147.

[6] Bhattacharya, B. N. and Gordy, W.: 1960, Phys. Rev. 119, 144.

[7] Simmons, J. W., Anderson, W. E., and Gordy, W.: 1950, Phys. Rev. 77, 77, Errata, Phys. Rev. 86, 1055.

[8] Lilley, A. E. and Palmer, P.: 1968, Astrophys. J. Supplement 16, 143.

[9] Cheung, A. C., Rank, D. M., Townes, C. H., Thornton, D. D., and Welch, W. J.: 1968, Phys. Rev. Letters 21, 1701.

[10] Wilson, R. W., Jefferts, K. B., and Penzias, A. A.: 1970, Astrophys. J. 161, L43.

[11] Zuckerman, B., Palmer, P., Snyder, L. E., and Buhl, D.: 1969, Astrophys. J. 157, L167.

[12] Jefferts, K. B., Penzias, A. A., and Wilson, R. W.: 1970, Astrophys. J. 161, L87.

\section{DISCUSSION}

Moffat: (1) I would like to appeal to the observers of galactic line sources to agree on some unified nomenclature for these objects. Names like SGR A (NH3-A) are confusing at best.

(2) Both Drs Wilson and Snyder have made the hypothesis that lines from the $\mathrm{C}^{12}$ isotopic species were saturated while the $\mathrm{C}^{13}$ species were not. If that were so, I think in Dr Wilson's data the $\mathrm{C}^{13} \mathrm{O}^{16}$ profiles in either velocity or position should be much narrower than the $\mathrm{C}^{12} \mathrm{O}^{16}$ profiles, whereas they seem to have similar shapes. However, the $\mathrm{C}^{12} \mathrm{O}^{18}$ profiles do seem much narrower. Thus I question the hypothesis of saturation in the $\mathrm{C}^{12}$ lines alone. 